\title{
IDENTIFICAÇÃO DE MARCADORES RAPD LIGADOS A UM GENE DE RESISTÊNCIA AO CANCRO DA HASTE DA SOJA*
}

\author{
GERALDO A. CARVALHO ${ }^{1 * *}$, TUNEO SEDIYAMA ${ }^{2}$, ANA LILIA ALZATE MARIN ${ }^{1}$, \\ EVERALDO G. BARROS ${ }^{1,3}$ \& MAURILIO A. MOREIRA ${ }^{1,4}$
}

${ }^{1}$ Instituto de Biotecnologia Aplicada à Agropecuária - BIOAGRO/Universidade Federal de Viçosa (UFV); ${ }^{2}$ Departamento de Fitotecnia/UFV; ${ }^{3}$ Departamento de Biologia Geral/UFV; ${ }^{4}$ Departamento de Bioquímica e Biologia Molecular/UFV, CEP 36571-000, Viçosa, MG, fax (031) 3899-2864, e-mail: moreira@ufv.br

(Aceito para publicação em 14/05/2002)

Autor para correspondência: Maurílio A. Moreira

CARVALHO, G.A., SEDIYAMA, T., ALZATE-MARIN, A. L., BARROS, E.G. \& MOREIRA, M.A. Identificação de marcadores RAPD ligados a um gene de resistência ao cancro da haste da soja. Fitopatologia Brasileira 27:474-478. 2002.

\section{RESUMO}

O cancro da haste da soja (Glycine max) é uma importante doença causada pelo fungo Diaporthe phaseolorum f. sp. meridionalis/Phomopsis phaseoli f. sp. meridionalis. Visando identificar marcadores RAPD associados a genes de resistência ao cancro da haste, causado pelo isolado $\mathrm{CH} 8$, presentes na linhagem UFV 91-61, foi realizado, inicialmente, um estudo sobre a herança da resistência, por meio do cruzamento desta linhagem com a variedade suscetível Paranaíba. Os resultados indicaram que um gene dominante controla a resistência a este isolado. Através de análises com marcadores moleculares na população $F_{2}$ foram identificados dois marcadores RAPD produzidos pela amplificação do primer OPAB19. Os dois fragmentos de DNA de aproximadamente 1.150 e $1.320 \mathrm{pb}$ produzidos por este primer estão ligadas em fases de repulsão e acoplamento, respectivamente, a uma distância de 4,7 cM do gene de resistência da linhagem UFV 91-61. Estes marcadores poderão ser usados para monitorar a introgressão deste gene em cultivares de soja adaptados e abre a possibilidade de uma sistemática procura de marcadores ligados a outros genes de resistência para o cancro da haste da soja, os quais poderiam ser posteriormente piramidados num único background genético.

Palavras-chave adicionais: Diaporthe phaseolorum f. sp. meridionalis, Phomopsis phaseoli f. sp. meridionalis, Glycine max, resistência a doenças da soja.

\section{ABSTRACT \\ Identification of RAPD markers linked to a soybean stem canker resistance gene}

Soybean stem canker is a serious soybean (Glycine max) disease caused by the fungi Diaporthe phaseolorum f. sp. meridionalis/Phomopsis phaseoli f. sp. meridionalis. We have crossed the soybean resistant line UFV 91-61 with the susceptible cultivar Paranaiba, and analyze the F2 population in order to understand the genetics underlying resistance to this pathogen (isolate $\mathrm{CH} 8$ ) and to identify molecular markers linked to it. The results indicate that a single dominant gene controls resistance to this isolate. RAPD analysis in the $\mathrm{F}_{2}$ population identified two DNA fragments of approximately 1,150 and 1,320 bp of primer OPAB19 linked in the repulsion and coupling phase at $4.7 \mathrm{cM}$ of the resistance gene of line UFV 91-61. These markers will be very useful for monitoring the introgression of this gene into soybean adapted cultivars, and open up the possibility for a systematic search for markers linked to other resistance genes for stem canker that could be pyramided into the same genetic background.

\section{INTRODUÇÃO}

A soja [Glycine max (L.) Merrill] é um dos produtos agrícolas de maior importância para a economia nacional. $\mathrm{O}$ Brasil é o segundo maior produtor e exportador mundial de soja, com uma produção estimada em torno de 36 milhões de toneladas de grãos, em uma área de, aproximadamente, 13,7 milhões de hectares na safra 2000/2001 (Embrapa Soja, 2001).

A expansão da soja para novas áreas, principalmente para as regiões mais quentes e úmidas dos cerrados, tem contribuído para o aumento da incidência de várias doenças.

\footnotetext{
* Apoio financeiro do PADCT/FINEP

** Bolsista do CNPq
}

Atualmente, uma dessas doenças, potencialmente mais importante no sentido de promover grandes perdas na produção é o cancro da haste, causado por um fungo que apresenta duas fases de desenvolvimento: a fase teleomórfica, denominada de Diaporthe phaseolorum f. sp. meridionalis Cke \& Ell. e a fase anamórfica, denominada de Phomopsis phaseoli f. sp. meridionalis (Yorinori et al., 1993).

O patógeno foi detectado pela primeira vez no Brasil no estado do Paraná, na safra de 1989/90 e, atualmente, encontra-se disseminado em todas as áreas produtoras de soja, desde Balsas (MA) a Pelotas (RS), demonstrando rápida disseminação. Dependendo das condições climáticas e da variedade, a doença pode causar a morte prematura das plantas, causando em certos casos, até $100 \%$ de perda na 
produção (Yorinori, 1990).

Sem dúvida, uma das maneiras mais eficientes e econômicas de controlar a doença é por meio do uso de cultivares resistentes. Por isso, estratégias devem ser combinadas para auxiliar programas de melhoramento que visem a obtenção de cultivares comerciais resistentes, adaptadas a várias regiões do país.

Marcadores moleculares do tipo RAPD ("Random Amplified Polymorphic DNA"), ligados a genes que condicionam resistência a doenças em várias culturas têm sido identificados, utilizando a técnica "Bulk Segregant Analysis" (BSA) desenvolvida por Michelmore et al. (1991). Utilizando esta estratégia, Alzate-Marin et al. (1999) identificaram marcadores RAPD em acoplamento e em repulsão ligados ao gene $C o-6$ presente na variedade $\mathrm{AB} 136$ de feijoeiro comum que confere resistência a várias raças de Colletotrichum lindemuthianum (Sacc. \& Magnus) Lams. Scrib. Pela mesma estratégia, Schuster et al. (2001) mapearam um QTL de efeito maior, localizado no grupo de ligação D2 da soja, que explica mais de $40 \%$ da resistência à raça 14 do nematóide de cisto (NCS). A identificação de marcadores moleculares ligados a genes de resistência permite a seleção de genótipos resistentes e possibilita a piramidação desses genes em cultivares suscetíveis. Estes marcadores têm diversas vantagens em relação aos marcadores fenotípicos tradicionais, pois podem ser identificados em qualquer estádio de desenvolvimento da planta, não são afetados pelo ambiente e não interagem epistaticamente (Williams et al., 1993).

Este trabalho teve como objetivos definir o padrão de herança da resistência da linhagem de soja UFV 91-61 ao cancro da haste causado pelo isolado de D. phaseolorum f.sp. meridionalis $\mathrm{CH} 8$ e identificar marcadores RAPD ligados ao(s) gene(s) que confere $(\mathrm{m})$ resistência. Estes marcadores, uma vez identificados, serão úteis como metodologia alternativa, na seleção de genótipos resistentes em programas de melhoramento visando a obtenção de cultivares resistentes.

\section{MATERIAL E MÉTODOS}

\section{Material vegetal e avaliação da doença}

As sementes da linhagem de soja UFV 91-61, resistente ao isolado $\mathrm{CH} 8$, e da cultivar Paranaíba, suscetível a esse isolado, foram fornecidas pelo Banco de Germoplasma do Departamento de Fitotecnia da UFV. Esses dois genótipos foram cruzados entre si, em casa de vegetação, e os indivíduos F1 foram autofecundados para obtenção de sementes F2.

O isolado utilizado para as inoculações foi $D$. phaseolorum $\mathrm{f}$. sp. meridionalis $\mathrm{CH} 8$, obtido da cultivar Davis, proveniente do Município de Palmeiras (PR), em 1989, foi cedido pelo Dr. José Tadashi Yorinori da Embrapa Soja, Londrina. Este isolado é considerado padão de patogenicidade para o cancro da haste da soja. O fungo foi mantido em meio de cultura, composto por batata-dextrose-ágar (BDA) a temperatura ambiente. $\mathrm{O}$ inóculo foi produzido em palito de dente colonizado com o micélio do fungo, de acordo com a técnica descrita por Crall (1952) e Keeling (1982), modificada por Yorinori (1991).

Sementes F2, derivadas de quatro plantas F1, foram plantadas em casa de vegetação e inoculadas no estádio V3 (Fehr \& Caviness, 1979). As inoculações foram feitas pela manhã, introduzindo-se na haste principal das plantas, a 10 $\mathrm{mm}$ abaixo das folhas unifolioladas, um palito de dente colonizado pelo fungo. As plantas inoculadas foram mantidas em local saturado de umidade por um período de três dias. As avaliações iniciaram-se 15 dias após as inoculações e consistiram na observação visual para presença de lesão no ponto de inoculação. As plantas inoculadas que não apresentavam lesões foram consideradas resistentes e as plantas com qualquer grau de lesão, incluindo plantas mortas, foram consideradas suscetíveis.

Plantas de 30 famílias da geração F3, originadas por autofecundação de 30 plantas da geração F2, consideradas resistentes, também foram inoculadas, com o objetivo de distinguir plantas resistentes homozigotas de plantas resistentes heterozigotas da geração F2.

\section{Composição dos bulks e análises por RAPD}

O DNA foi extraído a partir de cada indivíduo da população F2 de acordo com a metodologia descrita por Doyle \& Doyle (1990), com algumas modificações. A qualidade do DNA foi monitorada por eletroforese, em gel de agarose $(0,8 \%)$, e corado com brometo de etídio. Após essas etapas foram feitas soluções de trabalho de cada amostra de DNA, na concentração de $10 \mathrm{ng} / \mu \mathrm{l}$.

Dois bulks foram contruídos com amostras de DNA de folhas de plantas da geração F2 homozigotas para resistência/suscetibilidade ao cancro da haste, sendo que cada bulk (resistente e suscetível) continha DNA de sete plantas, de acordo com a metodologia de Michelmore et al. (1991). Os bulks foram analisados com 600 primers.

As reações de amplificação foram feitas em termociclador Perkin-Elmer 9600 (Norwalk, Conn, EUA), programado para 40 ciclos de $15 \mathrm{~s}$ a $94{ }^{\circ} \mathrm{C}$ (desnaturação do DNA); $30 \mathrm{~s}$ a $35^{\circ} \mathrm{C}$ (pareamento do primer ao DNA molde); e $1 \mathrm{~min}$ a $72^{\circ} \mathrm{C}$ (extensão dos primers). Cada reação de $25 \mu 1$ continha $10 \mathrm{mM}$ de Tris- $\mathrm{HCl}(\mathrm{pH} \mathrm{8,0)}, 50 \mathrm{mM}$ de $\mathrm{KCl}, 2 \mathrm{mM}$ de $\mathrm{MgCl}_{2}, 100 \mu \mathrm{M}$ de cada desoxirribonucleosídeo trifosfato, $0,4 \mu \mathrm{M}$ de um único primer (Operon Technologies, Alameda, CA, EUA), uma unidade da enzima Taq DNA polimerase e 30 ng de DNA.

Os fragmentos de DNA amplificados foram separados por eletroforese em géis de agarose $1,2 \%$ em tampão TBE (Tris-Borato 0,09M e EDTA 0,002M), a $100 \mathrm{~V}$, por um período de, aproximadamente, $4 \mathrm{~h}$. O DNA do bacteriófago lambda, clivado com as enzimas de restrição HindIII, BamHI e EcoRI foi utilizado como padrão para estimar o tamanho dos fragmentos. Após a eletroforese, os géis que continham brometo de etídio $(0,2 \mathrm{ng} / \mathrm{ml}$ de gel $)$ foram fotografados sob luz ultravioleta, usando filme "polaroid" tipo 667.

\section{Análise de segregação}

O teste de Qui-quadrado foi usado para definir a 


\section{G.A. Carvalho et al.}

herança da resistência ao cancro da haste presente na linhagem de soja UFV 91-61. A freqüência de recombinação entre o marcador identificado e o gene de resistência foi calculada usando 108 indivíduos da população F2 originada do cruzamento entre a linhagem UFV 91-61 e a cultivar Paranaíba. A distância foi estimada usando-se o programa MAP MAKER III, com um LOD score mínimo de 3,0, adotando-se a função de mapeamento de Kosambi (Lander et al., 1987)

\section{RESULTADOS E DISCUSSÃO}

Verificou-se que entre 235 plantas inoculadas, 168 mostraram-se resistentes e 67 mostraram-se suscetíveis ao isolado $\mathrm{CH} 8$, segregando, portanto, numa proporção fenotípica próxima a três plantas resistentes para uma suscetível (Tabela 1), indicando que a herança é monogênica com dominância completa. Esta hipótese também foi confirmada nos resultados das inoculações, com o mesmo isolado, das 30 famílias da geração $\mathrm{F} 3$ provenientes de 30 plantas da geração F2. Destas famílias, nove não segregaram e 21 segregaram para resistência ao cancro da haste, resultando numa proporção fenotípica próxima a 1:2 (Tabela 1).

Os resultados deste experimento estão em conformidade com aqueles obtidos por Oliveira (1993), onde o referido autor conclui que a resistência ao cancro da haste na linhagem de soja J-118 é controlada por um gene dominante. Já Kilen \& Hartwig (1987), Bowers et al. (1993) e Siviero (1992) observaram dois genes dominantes controlando a resistência ao cancro da haste nos genótipos de soja TracyM, Crockett, Dowling, IAC-Foscarin e Primavera.

A observação de que a resistência ao cancro da haste da soja é controlada por poucos genes, pode facilitar a obtenção de cultivares resistentes a essa doença. A transferência de genes de resistência para cultivares suscetíveis pode ser feita, de modo eficiente, utilizando-se o método do retrocruzamento. No entanto, quando se tem dois genes conferindo resistência, a dificuldade dos programas de retrocruzamentos é a identificação dos genes que estão sendo selecionados. Tanto no caso da identificação de um gene como na identificação de dois genes, marcadores moleculares ligados aos genes de resistência podem ser uma ferramenta muito útil na identificação e monitoramento de tais genes.

Para identificação de marcadores moleculares ligados

TABELA 1 - Dados de segregação do caráter resistência ao cancro da haste da soja (Glycine max) na população F2 e em famílias F3 originadas de plantas $\mathrm{F} 2$ resistentes, do cruzamento entre Paranaíba x UFV 91-61

\begin{tabular}{lccccc}
\hline \hline População & Geração & $\begin{array}{c}\text { Razão } \\
\text { Observada }\end{array}$ & $\begin{array}{c}\text { Razão } \\
\text { esperada }\end{array}$ & $\chi^{2}$ & Probabilidade \\
\hline Paranaíba x UFV91-61 & F2 & 168R:67S & $3: 1$ & 1,54 & 21,39 \\
Paranaíba x UFV91-61 & F3 & 9NS: 21SG & $1: 2$ & 0,15 & 69,85 \\
\hline
\end{tabular}

${ }^{\mathrm{a} R}$-Resistente; S- Suscetível; bNS- Não segregando; SG- Segregando ao gene de resistência da linhagem UFV 91-61, as amostras de DNA contidas nos dois bulks de plantas F2 (resistente / suscetível), foram então amplificadas com 600 primers de seqüência aleatória. Considerando que para cada primer foram amplificados em média, cerca de seis fragmentos de DNA, foram analisados em torno de 3.600 loci. No entanto, a maioria dos loci mostraram-se monomórficos e não informativos para diferenciar os dois bulks.

Somente o primer OPAB19 (5'ACACCGATGG3'), detectou dois fragmentos polimórficos de DNA. O marcador RAPD de 1320 pares de bases está presente na linhagem resistente UFV91-61 (Figura 1, coluna 1), no bulk de indivíduos resistentes em homozigose para o alelo na população F2 (coluna 3) e nos indivíduos resistentes homozigotos da população F2 (colunas RHm). O marcador RAPD de $1150 \mathrm{pb}$ está presente na variedade suscetível Paranaíba (coluna 2), no bulk de indivíduos suscetíveis da população F2 (coluna 4) e nos indivíduos suscetíveis da população F2 (colunas S). Tanto o marcador de 1320 pb quanto o marcador de 1150 pb estão presentes nos indivíduos resistentes heterozigotos para o caráter em estudo na população F2 (colunas RHt).

Análise de co-segregação em 108 indivíduos da população F2 demonstrou que a distância entre ambos os marcadores e o locus de resistência é de aproximadamente 4,7 centiMorgans (cM). Apesar da distância genética indicar a possibilidade de ocorrer recombinação entre os marcadores e os genes de resistência/suscetibilidade, estes poderão ser usados na seleção indireta em programas de melhoramento. Um fragmento intermediário entre os fragmentos OPAB $19{ }_{1320}$ e OPAB $19_{1150}$, foi observado nos indivíduos resistentes heterozigotos para o gene (Figura 1). Resultados similares foram observados por Michelmore et al. (1991) em alface (Lactuca sativa L.), onde indivíduos heterozigotos para o alelo Dm5/8 apresentavam uma banda que não estava presente nos progenitores. A observação de que o primer OPAB19 gerou 2 produtos de amplificação com tamanhos diferentes, levanta a hipótese que eles correspondem a dois alelos de um mesmo locus.

Uma vez que é possível distinguir indivíduos homozigotos de heterozigotos, com os marcadores OPAB19 ${ }_{1320} \mathrm{e}$ OPAB $19_{1150}$, estes poderão ser de grande valia em programas de melhoramento que visam obter linhagens resistentes ao cancro da haste utilizando-se como progenitor a linhagem UFV 91-61 e cultivares que apresentem padrão de amplificação similar ao da variedade Paranaíba.

A linhagem UFV 91-61, do programa de melhoramento do sabor da soja para a agroindústria em desenvolvimento na UFV, não contém as isoenzimas lipoxigenases (LOX) 2 e 3 em suas sementes. Esta linhagem originou-se do cruzamento entre a cultivar Cristalina (que possui LOX 1, 2 e 3 em suas sementes e é altamente suscetível ao cancro da haste) com o progenitor Ichigowase (que não possui LOX $3 \mathrm{e}$ é resistente ao cancro da haste), intercalados de autofecundações e seleção para ausência de LOX 3. Apesar de Ichigowase ser resistente ao cancro da haste, todas as 
Identificação de marcadores RAPD ligados a um gene de resistência...

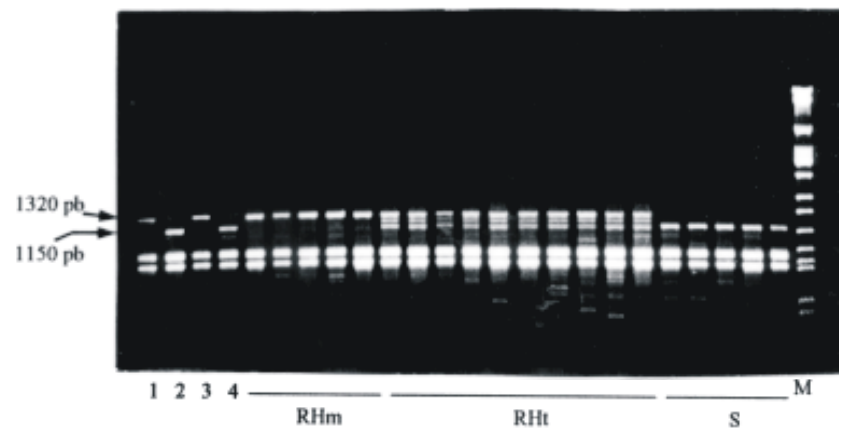

FIG. 1 - Padrão de amplificação de DNA de cultivares de soja (Glycine max) pela técnica de RAPD utilizando o primer OPAB19. Os dois marcadores encontrados estão indicados pelas setas. As colunas 1, 2, 3 e 4 contêm os produtos da amplificação do DNA da linhagem UFV91-61, Paranaíba, bulk resistente e bulk suscetível, respectivamente. RHm contém os produtos da amplificação dos indivíduos resistentes homozigotos, RHt dos indivíduos resistentes heterozigotos e $\mathrm{S}$ dos indivíduos suscetíveis. "M" corresponde ao padrão de massa molecular proveniente da digestão do DNA do fago lambda com Bam HI, Hind III e Eco RI.

linhagens resultantes mostraram ser suscetíveis (observações pessoais). Estas linhagens suscetíveis sem LOX 3 foram cruzadas com o genótipo PI 86023 (sem LOX 2) seguidas de seleção na geração F2 para ausência de LOX 2 e 3. A partir da geração F2, foram feitas várias gerações de autofecundações e seleções até a geração F8, na qual foram obtidas várias linhas puras sem LOX 2 e 3, entre elas a linhagem UFV 91-61 (resistente ao cancro da haste). Assim, concluíu-se que o gene de resistência ao cancro da haste da linhagem UFV 91-61 tinha como origem o genótipo PI 86023.

Pode ser observado, também, que PI 86023 apresenta o marcador OPAB19 ${ }_{1320}$ (Figura 2, coluna 2). O fato de nenhuma linhagem de soja sem LOX 3 ser resistente ao cancro da haste, provavelmente, ocorreu por causa da perda do gene de resistência durante as gerações de retrocruzamentos e autofecundações com seleção somente para ausência de LOX 3 , visto que Ichigowase, progenitor doador do gene recessivo que determina ausência de LOX 3, é resistente ao cancro da haste e também apresenta a banda OPAB19 ${ }_{1320}$ (Figura 2, coluna 1). Este fato comprova que o gene de resistência ao cancro da haste, identificado neste trabalho, e o gene que codifica para LOX 3 não estão ligados.

Embora os dois marcadores identificados neste trabalho mostraram-se codominantes para o cruzamento UFV 91-61 x Paranaíba, o marcador em repulsão (fragmento de $1.150 \mathrm{pb})$ poderá não ser útil para outros cruzamentos envolvendo a linhagem UFV 91-61 com outras variedades suscetíveis. Como exemplo disto, a variedade Cristalina, embora sendo suscetível, não apresenta o alelo OPAB19 ${ }_{1150}$
$\begin{array}{llllll}M & 1 & 2 & 3 & 4 & 5\end{array}$

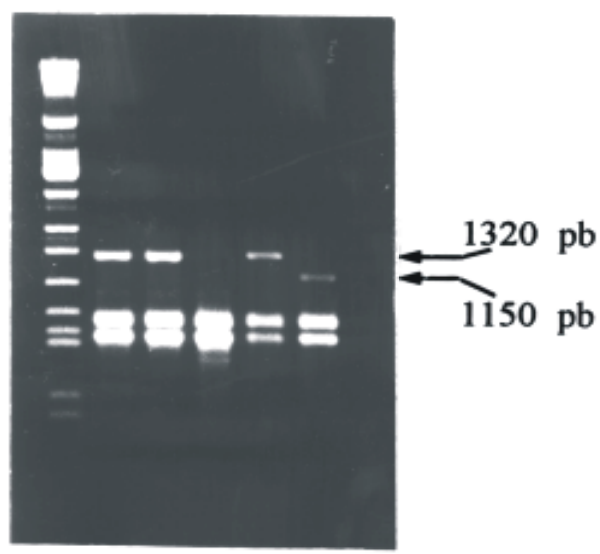

FIG. 2 - Padrão de bandas obtido após amplificação com o primer OPAB19 dos genótipos de cultivares de soja (Glycine max) 1-Ichigowase, 2- PI 86023, 3Cristalina, 4- UFV91-61, 5- Paranaíba , Mmarcador de massa molecular (fago lambda digerido com Bam HI, Hind III e Eco RI).

(Figura 2). Portanto, em cruzamentos com outras variedades suscetíveis que apresentam o mesmo padrão de amplificação da Cristalina, o marcador comportar-se-á como dominante, não distinguindo planta resistente em homozigose de planta resistente em heterozigose para o caráter em estudo.

\section{REFERÊNCIAS BIBLIOGRÁFICAS}

ALZATE-MARIN, A.L., MENARIM, H., CARVALHO, G.A., PAULA JÚNIOR, T.J., BARROS, E.G. \& MOREIRA, M.A. Improved selection with newly identified RAPD markers linked to resistance gene to four pathotypes of Colletotrichum lindemuthianum in common bean. Phytophatology 89:281-285. 1999.

BOWERS, Jr, G.R., NGLELEKA, K. \& SMITH, O.D. Inheritance of stem canker resistance in soybean cultivars Crokett and Dowling. Crop Science 33:67-69. 1993.

CRALL, J. M. A toothpick method of inoculation. Phythopathology 42:5-6. 1952

Embrapa Soja, Documentos 167. Tecnologias de Produção de SojaRegião Central do Brasil - 2001/2002. Embrapa Soja, Londrina, 2001.

DOYLE, J.J. \& DOYLE, J.L. Isolation of plant DNA from fresh tissue. Focus 12:13-15. 1990.

FEHR, W.R. \& CAVINESS, C.E. Stage of soybean development. Ames: Iowa State University, Cooperative Extension Service, 1979.

KEELING, B.L. Seedling test for resistance to soybean stem canker caused by Diaporthe phaseolorum var. caulivora. Phytopathology 72:807-809. 1982.

KILEN, T.C. \& HARTWIG, E.E. Identification of single genes controlling resistance to stem canker in soybean. Crop Science 27:863-867.1987.

LANDER, E.S., GREEN, P., ABRAHAMSON, J., BARLOW, A., DALY, M.J., LINCOLN, S.E. \& NEWBURGH, L. 


\section{G.A. Carvalho et al.}

MAPMAKER: An interactive computer package for constructing primary genetic linkage maps of experimental and natural populations. Genomics 1:174-181. 1987.

MICHELMORE, R., PARAN, I. \& KESELLI, V. Identification of markers linked to disease-resistance genes by bulked segregant analysis: A rapid method to detect markers in specific genomic regions by using segregating populations. Proceedings National Academy of Science, USA 88:9828-9832. 1991.

OLIVEIRA, A.L. Herança da resistência ao cancro da haste da soja [Glycine $\max$ (L.) Merrill]. (Tese de Mestrado). Jaboticabal. UNESP. 1993.

SIVIERO, A. Herança da resistência da soja a Diaporthe phaseolorum f. sp. meridionalis. (Tese de Mestrado). Piracicaba. ESALQ/ USP. 1992.

SCHUSTER, I., ABDELNOOR, R.V., MARIN, S.R.R., CARVALHO, V.P., KIIHL, R.A.S., SILVA, J.F.V., SEDIYAMA, C.S.,
BARROS, E.G. \& MOREIRA, M.A. Identification of a new major QTL associated with resistance to soybean cyst nematode (Heterodera glycines). Theoretical and Applied Genetics 102:9196. 2001.

WILLIAMS, J.G.K., HANAFEY, M.K., RAFALSKI, J.A. \& TINGEY, S.C. Genetic analysis using Random Amplified Polymorphic DNA Markers. Methods in Enzimology 218:704-740. 1993.

YORINORI, J.T. Cancro da haste da soja. Londrina. Embrapa Soja, Comunicado técnico. 1990.

YORINORI, J.T., CHARCHAR, M.D., NASSER, L.C.B. \& HENNING, A.A. Doenças da soja e seu controle. In: Arantes, N.E. \& Souza, P.I.M. (Eds) Cultura da soja nos cerrados. Piracicaba. Potafos. 1993. pp. 333-397.

YORINORI, J.T. Metodologia de produção de Diaporthe phaseolorum, f. sp. meridionalis. Fitopatologia Brasileira 16:58. 1991. (Resumo). 